\title{
28 Research Square \\ Incubation Onset Influences Maternal Investment in Eggs and Egg and Nestling Survival in an Altricial Bird
}

Takahiro Kato ( $\boldsymbol{\nabla}$ t.kato.n25@gmail.com )

The Graduate University for Advanced Studies $\square$ SOKENDAl https://orcid.org/0000-0002-2520-593X

\section{Shin Matsui}

Tokai University

Nobuyuki Kutsukake

The Graduate University for Advanced Studies, SOKENDAI

\section{Ryota Dobashi}

Rikkyo University

Keisuke Ueda

Rikkyo University

\section{Research Article}

Keywords: Life history, parental investment, resource allocation, egg viability, hatching asynchrony, incubation onset

Posted Date: March 11th, 2021

DOI: https://doi.org/10.21203/rs.3.rs-261537/v1

License: (ㅇ) (7) This work is licensed under a Creative Commons Attribution 4.0 International License. Read Full License 


\section{Abstract}

Many birds initiate incubation before clutch completion which results in asymmetric survival of eggs and nestlings within the clutch. When parents start incubating before clutch completion, low survival is expected of the nestlings hatched from eggs laid after the onset of incubation due to hatching asynchrony. Conversely, eggs laid before the onset of incubation may have a lower survival because of extrinsic factors (e.g. ambient temperature and microbial infection). Many studies investigating the allocation of parental investment have hypothesized two different strategies wherein parents allocate investment that favors eggs/nestlings with high survival prospects or compensates for the disadvantages of eggs/nestlings with low survival prospects. Although birds could take different strategies based on incubation onset within the same breeding attempt, this idea has never been tested. We conducted an observational study to investigate the effects of incubation onset on the survival of eggs laid before and after incubation onset and parental egg allocation in the altricial wryneck Jynx torquilla. We found that survival decreased in the eggs laid earlier or later than the day of incubation onset within the clutch. Because egg volume increased with laying sequence, egg volume and the survival of eggs laid before incubation onset were positively associated, whereas egg volume and the survival of eggs laid after incubation onset were negatively associated. Furthermore, late-hatching nestlings grew to similar weights to early-hatching nestlings. These suggest that females proportionately invested in egg size before incubation onset, but that investment in egg size after incubation onset was compensatory. Our observational study proposes a possibility that female wrynecks adopt two different investment strategies before and after incubation onset during a breeding attempt.

\section{Introduction}

The relationship between parental investment and offspring quality has been investigated in numerous studies that have demonstrated how parents should allocate their investment to maximize their fitness (Temme 1986; Haig 1990; Clutton-Brock 1991; Stearns 1992; Royle et al. 2012). Parents allocate their investment according to factors associated with offspring reproductive value such as mate quality (differential allocation: Burley 1986; Sardell and DuVal 2013), brood size (Coleman et al. 1985; Carlisle 1985), offspring size, age, breeding attempt onset (Winkler 1987), parentage (Westneat and Sherman 1993), offspring sex (Komdeur et al. 1997), and predation risk (Slagsvold 1982; Haight 2018). The allocation of parental investment has been mainly investigated in avian offspring (Slagsvold and Lifjeld 1989; Viñuela 1997; Sardell and DuVal 2013). In birds, the timing of incubation onset is a key event explaining the allocation of parental investment and is a crucial determinant in egg and nestling survival as it realizes asymmetric egg and nestling survivability with respect to egg-laying sequence (Aldredge 2017).

The clutch is completed over several days as female birds cannot lay more than one egg per day (Clark and Wilson 1981). Many birds start incubation before clutch completion in order to shorten the breeding period and reduce the risk of egg or nestling depredation ("nest failure hypothesis"; Clark and Wilson 1981). Alternatively, parents may avoid embryonic death resulting from the failure to incubate eggs that have been laid early ("egg viability hypothesis"; Arnold et al. 1987; Veiga 1992). Incubation onset before clutch completion causes asynchrony in hatching. Late-hatching nestlings incur a competitive disadvantage compared to their earlyhatching siblings (Oddie 2000; Bebbington et al. 2017). Therefore, the survival prospect of eggs laid after incubation onset should be negatively correlated with the egg-laying sequence because of this hatching 
asynchrony. Previous studies have hypothesized that increasing egg size in the laying sequence is a breeding strategy compensating for the disadvantages resulting from hatching asynchrony (Stoleson and Beissinger 1995). In this scenario, female parents increase the size of eggs which are expected to be delayed in hatching in order to increase the body weight of late-hatched nestlings. In other forms, it has been reported as parental compensation, such as an elevation of testosterone level in the yolk to increase the growth of late-hatching nestlings (Schwabl 1993) or preferential provisioning for late-hatching nestlings (Gottlander 1987). Hereafter, this hypothesis is referred to as the "compensatory investment hypothesis" in which parents allocate a comparatively greater investment to eggs or nestlings with poorer survival prospects within the clutch.

On the other hand, the survival of eggs laid before incubation onset should decrease when the egg-laying sequence is early because eggs laid before incubation onset are susceptible to microbial infection (Cook et al. 2005; D'Alba et al. 2010), ambient temperature (Webb 1987), weather conditions (Wang and Beissinger 2009; Coe et al. 2015), and predation or nest site takeover (Clark and Wilson 1981). In these cases, early-hatching nestlings require no compensation for their size. Instead, female parents may allocate investment in egg size according to survival prospects of the eggs laid before incubation onset. Declining egg size over the laying sequence in some birds (Poole 1982; Meathrel and Ryder 1987; Svagelj et al. 2015; Djerdali et al. 2016) is explained by unpredictable breeding environments ("brood reduction hypothesis"; Lack 1947; Slagsvold et al. 1984). This hypothesis proposes that late-hatching nestlings are surplus and survive only when there is a lot of food available for the parents to feed their nestlings. Unlike the aforementioned "compensatory investment hypothesis", this theory (the "proportional investment hypothesis") suggests that parents should allocate comparatively less investment to eggs or nestlings with lower survival prospects within the clutch.

Collectively, there are two different investment strategies in egg and nestling size. As mentioned, the timing of the onset of incubation is a crucial determinant in the survival prospects of the eggs and nestlings. Therefore, birds that initiate incubation before clutch completion could adopt both (different) investment strategies in a breeding attempt. However, this possibility has never been tested.

We conducted an observational study to test the hypothesis that the survival prospects of the eggs are highest for eggs laid on the day of incubation onset in the wryneck Jynx torquilla, an altricial Piciformes species. The wryneck is migratory bird, and it returned to our study site in April. Wrynecks nest in a cavity and are social monogamous. Both sexes incubate eggs and provide foods for nestlings. We investigated the relationships among incubation onset, egg volume, egg viability, hatching asynchrony, nestling growth, and fledging success. We predicted that the viability of eggs laid before incubation onset until hatching would increase with a decrease of temporal distance (the number of days between laying and the day of incubation onset within the clutch), but the viability of eggs laid after incubation onset until hatching would be constant, irrespective of temporal distance (Prediction 1, Fig. 1a). Contrary to these, we predicted that the survival of nestlings hatched from eggs laid before incubation onset until fledging would be constant, irrespective of temporal distance, but the survival of nestlings hatched from eggs laid after incubation onset until fledging would decrease with an increase of temporal distance (Prediction 2, Fig. 1b).

If the survival of eggs laid before incubation onset decreases (Prediction 1) and the survival of nestlings hatched from eggs laid after incubation onset decreases (Prediction 2), the viability of eggs from laying to fledging would be highest for eggs laid on the day of incubation onset (Fig. 1c). In this case, when female parents only adopt proportional investment through egg laying, egg size and egg viability until fledging should 
show a positive correlation (Fig. 2a: the size of eggs laid before incubation onset should increase with decreasing temporal distance, and the size of eggs laid after incubation onset should decrease with increasing temporal distance). Contrary to this, when female parents only adopt compensatory investment, egg size and egg viability until fledging should show a negative correlation (Fig. 2b: the size of eggs laid before incubation onset should decrease with increasing temporal distance, and the size of eggs laid after incubation onset should increase with decreasing temporal distance). If female parents adopt different investment strategies for eggs laid before and after the onset of incubation, egg size should show mixed patterns (Fig. 2c, d). Female parents may perform proportionate investments in egg volume before incubation onset because early-hatching nestlings require no compensation for their size. On the other hand, eggs laid after the onset of incubation require compensation for their size as this characteristic is positively associated with nestling body mass (Williams 1994; Styrsky et al. 1999). In this way, late-hatching nestlings can contend with sibling competition. Here, we predict that egg size should increase with decreasing temporal distance before incubation onset by proportional investment, and egg size should also increase with increasing temporal distance before incubation onset by compensatory investment (Prediction 3, Fig. 2c).

Furthermore, as the compensatory investment hypothesis predicts that female parents should produce comparatively larger eggs after the onset of incubation, there should be different growth patterns between the early- and late-hatching nestlings within the same clutch. We predicted that late-hatching nestlings will grow faster than early-hatching nestlings (Prediction 4) when the compensatory investment hypothesis is upheld.

\section{Materials And Methods}

\section{Fieldwork}

The study was conducted in Ogata Village, Akita Prefecture, Japan (40 $\left.00^{\prime} \mathrm{N}, 140^{\circ} 00^{\prime} \mathrm{E}\right)$ between May and July, 2012-2013. A total of 120 nest boxes were attached to pine trees Pinus thunbergii at $>50 \mathrm{~m}$ intervals over $7 \mathrm{~km}$ in a windbreak forest. The nest boxes were checked during the daytime until the wrynecks started laying eggs. The adult females lay one egg daily. The eggs were numbered with ink according to the order in which they were laid. The clutch size of this species was approximately nine (Table 1). They initiated incubation on the day of laying the sixth or seventh egg before the clutch was completed, although which sex started incubation is unclear (Table 1). Incubation onset in each clutch was judged by touching the eggs to detect heat. It approximately corresponded with the day of incubation onset judged by the temperature data loggers (KN laboratories Co., Ltd., Ibaraki, Osaka, Japan, Appendix 1), although the determination by touching delayed detection of the day of incubation onset by one day in some nests compared with that determined by the data logger. Within three days of clutch completion, egg lengths $(0.01 \mathrm{~mm})$ and breadths $(0.01 \mathrm{~mm})$ were measured and egg volumes $\left(0.51 \times\right.$ length $\times$ breadth $^{2}$; Hoyt 1979) were calculated. Nest boxes were checked daily for 10 days after clutch completion to determine the hatching date of each nestling. In order to increase the accuracy of the hatching date, we used the skin color of nestlings, since just-hatched nestlings tend to have reddish skin, especially in altricial birds. When we found that the degree of skin color was clearly different among nestlings, we regarded those with less reddish skin as having hatched on a previous date. On hatching day, the tarsus of each nestling was marked with colored ink. Nestling body weights were measured with a digital pocket scale to the nearest $0.1 \mathrm{~g}$ every 2 days after hatching (109 nestlings from 16 broods). 
Table 1

Clutch size, number of hatchlings, number of fledglings, and incubation onset in 2012 and 2013 clutches.

\begin{tabular}{|c|c|c|c|c|}
\hline & \multicolumn{2}{|c|}{2012} & \multicolumn{2}{|c|}{2013} \\
\hline & $\mathrm{N}$ & Mean \pm SD & $\mathrm{N}$ & Mean \pm SD \\
\hline Clutch size & 13 & $9.46 \pm 1.45$ & 18 & $9.44 \pm 1.89$ \\
\hline No. of hatchlings (hatching success) & 13 & $6.38 \pm 3.28(0.67)$ & 18 & $7.06 \pm 1.86(0.75)$ \\
\hline No. of fledglings (fledging success) & 13 & $5.69 \pm 3.25(0.75)$ & 14 & $4.79 \pm 3.04(0.65)$ \\
\hline Laying order at incubation onset & 10 & $7.10 \pm 1.10$ & 14 & $6.36 \pm 1.01$ \\
\hline \multicolumn{5}{|l|}{ Incubation period from incubation onset } \\
\hline 1 st hatching eggs & 9 & $12.44 \pm 1.51$ & 13 & $13.08 \pm 1.32$ \\
\hline 2nd hatching eggs & 8 & $13.00 \pm 1.29$ & 12 & $14.08 \pm 1.38$ \\
\hline 3rd hatching eggs & 5 & $13.80 \pm 1.48$ & 7 & $14.57 \pm 1.13$ \\
\hline 4th hatching eggs & 2 & $13.50 \pm 0.71$ & 0 & - \\
\hline
\end{tabular}

\section{Sex determination}

DNA was extracted from the blood of nestlings and nestlings that died from natural causes with a DNeasy Tissue Kit (QIAGEN, Tokyo, Japan). Their sex was determined by PCR (polymerase chain reaction) amplification by using the $C H D$ genes located on the $Z$ and $W$ sex chromosomes. Primers $1237 \mathrm{~L}$ and $1272 \mathrm{~L}$ were used. PCR amplification produced one male band and two female bands (Kahn et al. 1998; see Wink et al. 2011 for details on wryneck PCR methodology).

\section{Statistical analysis}

All statistical analyses were run in R v. 3.6.1 (R Core Team 2020). Linear mixed models (LMMs) and generalized linear mixed models (GLMMs) were constructed with the "glmer" and "Ime4" packages in R. For each egg within a focal nest, "temporal distance" was calculated. This parameter is the number of days between laying and the day of incubation onset within the focal nest; the range was between -7 and +6 days. This factor was used as a predictor in certain analyses. In some analyses, the effect of a two-way interaction between temporal distance and the laying period (before or after incubation onset) was examined because we predicted that hatching success, fledging success and egg size were different between before and after incubation onset. The possible effects of laying date on the first egg of each clutch ( 1 April = 1) and clutch size were set as additional predictors in order to control most models. Continuous predictors in the following analyses were divided by the standard deviation after subtracting the mean from raw values (centered and standardized; Schielzeth 2010). Study year and nest box identity were set as random effects in all analyses. A final model was selected by eliminating all nonsignificant variables with a likelihood ratio test (LRT) at $\mathrm{a}=0.05$.

\section{Effect of incubation onset on hatching success}


To test Prediction 1, a binomial GLMM with a logit link function was run. Egg hatching success $($ yes $=1$; no $=0$ ) was set as a response variable (192 eggs from 22 clutches). The predictor was the two-way interaction between temporal distance and the laying period (before (0) or after (1) incubation onset) of each egg in a focal nest.

\section{Effect of incubation onset on hatching delay and fledging success}

In order to test Prediction 2, we first estimated the effect of incubation onset on hatching delay by using a binomial GLMM. We used 120 eggs from 19 clutches that had hatched successfully. The response variable was whether hatching was delayed (1) or not (0) for each egg within a focal nest. The predictor was the laying period, before (0) or after (1) incubation onset.

Subsequently, two binomial GLMMs with a logit function were run to analyze the effect of hatching asynchrony on fledging success. There were 140 nestlings from 18 broods. The response variable was fledging success of nestlings (yes $=1 ;$ no $=0$ ). The predictor was hatching delay, which was defined as the number of days from the day of the first hatched nestlings to the day of hatching of the focal nestling within the focal nest (hatching delay for the first hatchling within a focal nest $=0$ ). We could neither determine the sex nor collect the DNA samples of 20 of the 140 nestlings, mainly due to their death at the early stages of development after hatching (16 of 20 nestlings) Considering a possibility that the mortality of nestlings at the early stage was correlated to hatching delay (10 of 16 dead nestlings had delayed hatching within focal clutch), we ran two models with nestling sex as a predictor and without nestling sex (female $=0$, male $=1$ ).

\section{Effect of incubation onset on egg volume}

To test Prediction 3, the effect of the two-way interaction between temporal distance and the laying period on egg volume was analyzed using an LMM. There were 157 eggs from 18 clutches. The response variable was egg volume. The predictor was the two-way interaction between temporal distance and the laying period of each egg in a focal nest.

\section{Effect of hatching delay on nestling growth}

For each nestling, growth (weight) was fitted to a logistic growth curve using the "nls" function in R. There were 106 nestlings from 16 broods. The data for each nestling that successfully fledged were used and nestlings were measured $\geq$ six times. The logistic growth curve was as follows:

$$
M_{t}=\frac{a}{1+b e^{-k t}}, \quad \text { (Equation 1) }
$$

where $M_{t}$ is the body weight at time $t$ (days of age), $a$ is an asymptotic value, $k$ is a constant proportional to overall growth, and $b$ is a constant such that the inflection point occurs at $t=0$ when $b=1$ (Ricklefs 1967).

The LMM was then run to estimate the effects of hatching asynchrony on nestling growth (Prediction 4). The response variables were the nestling asymptotic value $(a)$, the day of the inflection point, and the growth rate at the inflection point calculated from a logistic growth curve (Appendix 2). The predictor was the hatching delay for each nestling. Here, the effects of nestling sex, hatching date, and hatchling identity were controlled by designating them as additional predictors. 


\section{Results}

\section{Effect of incubation onset on hatching success}

The two-way interaction between temporal distance and laying period had a significant effect on hatching success (Table 2a). This indicates that hatching success increased with decreasing temporal distance before incubation onset, and then decreased with increasing temporal distance after incubation onset (Fig. 3).

Seventeen eggs laid before incubation onset did not hatch mainly due to hatching failure of embryos, where they grew in size just before hatching but did not hatch (12/ 17 eggs). Also, 17 eggs laid after incubation onset did not hatch, also mainly due to hatching failure of embryos (14 / 17 eggs, see Appendix 3 for causes of hatching failure.

Table 2

Effects of the temporal distance on (a) hatching success, (b) hatching delay, and (c) egg volume.

\begin{tabular}{|c|c|c|c|c|c|c|c|c|c|c|c|c|}
\hline & \multicolumn{4}{|c|}{ (a) Hatching success } & \multicolumn{4}{|c|}{ (b) Hatching delay } & \multicolumn{4}{|c|}{ (c) Egg volume } \\
\hline & $\begin{array}{l}\mathrm{b}( \pm \\
\mathrm{SE})\end{array}$ & $\chi^{2}$ & df & $P$ & $\begin{array}{l}\mathrm{b}( \pm \\
\mathrm{SE})\end{array}$ & $\chi^{2}$ & df & $\mathrm{P}$ & $\begin{array}{l}b( \pm \\
S E)\end{array}$ & $\chi^{2}$ & $\mathrm{df}$ & $P$ \\
\hline Intercept & $\begin{array}{l}1.63 \\
(0.34)\end{array}$ & & & & $\begin{array}{l}-2.14 \\
(1.23)\end{array}$ & & & & $\begin{array}{l}3.27 \\
(0.06)\end{array}$ & & & \\
\hline $\begin{array}{l}\text { Temporal } \\
\text { distance } \\
\times \text { Laying } \\
\text { period }\end{array}$ & $\begin{array}{l}-2.63 \\
(0.81)\end{array}$ & 11.72 & 1 & .001 & - & - & - & - & $\begin{array}{l}-0.12 \\
(0.08)\end{array}$ & 2.02 & 1 & .16 \\
\hline $\begin{array}{l}\text { Temporal } \\
\text { distance }\end{array}$ & $\begin{array}{l}0.89 \\
(0.32)\end{array}$ & - & - & - & - & - & - & - & $\begin{array}{l}0.19 \\
(0.03)\end{array}$ & 40.51 & 1 & $<.001$ \\
\hline $\begin{array}{l}\text { Laying } \\
\text { period }\end{array}$ & $\begin{array}{l}1.56 \\
(1.04)\end{array}$ & - & - & - & $\begin{array}{l}5.46 \\
(1.23)\end{array}$ & 61.40 & 1 & $<.001$ & $\begin{array}{l}-0.14 \\
(0.06)\end{array}$ & 5.43 & 1 & .02 \\
\hline $\begin{array}{l}\text { Laying } \\
\text { date }\end{array}$ & $\begin{array}{l}-0.21 \\
(0.19)\end{array}$ & 1.08 & 1 & .30 & $\begin{array}{l}0.14 \\
(0.44)\end{array}$ & 0.11 & 1 & .74 & $\begin{array}{l}0.07 \\
(0.05)\end{array}$ & 2.52 & 1 & .11 \\
\hline $\begin{array}{l}\text { Clutch } \\
\text { size }\end{array}$ & $\begin{array}{l}0.44 \\
(0.22)\end{array}$ & 3.83 & 1 & $>.05$ & $\begin{array}{l}-0.61 \\
(0.45)\end{array}$ & 1.83 & 1 & .18 & $\begin{array}{l}0.07 \\
(0.05)\end{array}$ & 2.07 & 1 & .15 \\
\hline
\end{tabular}

The laying period before incubation onset period (temporal distance $\leq 0$ ) was set as 0 and after incubation onset period (temporal distance $>0$ ) was set as 1 .

Predictors in the final model are shown in bold font.

\section{Effect of incubation onset on hatching delay and fledging success}

Eggs laid after incubation onset were likely to delay hatching (Table 2b; Fig. 4a). Fledging success significantly decreased with hatching delay within the same clutch in the model without the sex of nestlings as a predictor (Fig. 4b, LRT: hatching delay; $b \pm S E=-0.80 \pm 0.30 ; \chi^{2}=8.31 ; \mathrm{df}=1 ; P<0.01$ ). No other predictor was related to 
fledging success (LRT: number of hatchlings; $b \pm S E=0.56 \pm 0.34 ; \chi^{2}=2.69 ; \mathrm{df}=1 ; P=0.10 ;$ hatching date; $\mathrm{b} \pm$ $\left.\mathrm{SE}=0.17 \pm 0.41 ; \chi^{2}=0.08 ; \mathrm{df}=1 ; P=0.78\right)$. On the other hand, fledging success was not correlated to any predictors in the model with the sex of nestlings as a predictor (LRT: hatching delay; $\mathrm{b} \pm \mathrm{SE}=-2.29 \pm 1.75 ; \chi^{2}=$ 3.00; $\mathrm{df}=1 ; P=0.08$; number of hatchlings; $\mathrm{b} \pm \mathrm{SE}=0.54 \pm 0.64 ; \chi^{2}=0.71 ; \mathrm{df}=1 ; P=0.40$; hatching date; $\mathrm{b} \pm \mathrm{SE}=$ $-0.10 \pm 0.77 ; \chi^{2}=0.02 ; \mathrm{df}=1 ; P=0.90$; the sex of nestling (female =0); $\mathrm{b} \pm \mathrm{SE}=-0.02 \pm 1.51 ; \chi^{2}<0.01 ; \mathrm{df}=1 ; P=$ $0.99)$.

\section{Effect of incubation onset on egg volume}

The two-way interaction between temporal distance and laying period did not have a significant effect on egg volume (Table 2c). Egg volume increased with the laying sequence (Table 2c).

\section{Effect of hatching asynchrony on nestling growth}

Hatching delay were not significantly associated with the asymptotic value for nestling body weight (a) (Table 3a). Hatching delay was positively associated with their age at the inflection point (Table 3b). Thus, the younger hatchlings had later inflection points. Growth rate at the inflection point was not associated with hatching delay after controlling for the significant effect of brood size (Table 3c).

Table 3

Effects of hatching delay on (a) asymptotic value, (b) days of age at inflection point, and (c) growth rate at nestling growth inflection point.

\begin{tabular}{|c|c|c|c|c|c|c|c|c|c|c|c|c|}
\hline & \multicolumn{4}{|c|}{ (a) Asymptotic value } & \multicolumn{4}{|c|}{ (b) Inflection point } & \multicolumn{4}{|c|}{ (c) Growth rate } \\
\hline & $\mathrm{b}( \pm \mathrm{SE})$ & $x^{2}$ & df & $P$ & $\mathrm{~b}( \pm \mathrm{SE})$ & $\chi^{2}$ & $d f$ & $\mathrm{P}$ & $\begin{array}{l}\mathrm{b}( \pm \\
\mathrm{SE})\end{array}$ & $x^{2}$ & df & $P$ \\
\hline Intercept & $\begin{array}{l}31.07 \\
(0.72)\end{array}$ & & & & $\begin{array}{l}5.27 \\
(0.10)\end{array}$ & & & & $\begin{array}{l}3.37 \\
(0.08)\end{array}$ & & & \\
\hline $\begin{array}{l}\text { Hatching } \\
\text { delay }\end{array}$ & $\begin{array}{l}0.31 \\
(0.17)\end{array}$ & 3.24 & 1 & .07 & $\begin{array}{l}0.26 \\
(0.07)\end{array}$ & 11.56 & 1 & .001 & $\begin{array}{l}-0.03 \\
(0.03)\end{array}$ & 0.69 & 1 & .41 \\
\hline $\begin{array}{l}\text { No. } \\
\text { hatchlings }\end{array}$ & $\begin{array}{l}-0.12 \\
(0.69)\end{array}$ & 0.09 & 1 & .77 & $\begin{array}{l}-0.26 \\
(0.13)\end{array}$ & 0.47 & 1 & .49 & $\begin{array}{l}0.16 \\
(0.07)\end{array}$ & 4.88 & 1 & .03 \\
\hline $\begin{array}{l}\text { Nestling } \\
\text { sex }\end{array}$ & $\begin{array}{l}-0.03 \\
(0.33)\end{array}$ & 0.02 & 1 & .89 & $\begin{array}{l}-0.09 \\
(0.14)\end{array}$ & 0.42 & 1 & .52 & $\begin{array}{l}0.03 \\
(0.06)\end{array}$ & 0.18 & 1 & .67 \\
\hline $\begin{array}{l}\text { Hatching } \\
\text { date }\end{array}$ & $\begin{array}{l}0.58 \\
(0.58)\end{array}$ & 0.29 & 1 & .59 & $\begin{array}{l}-0.20 \\
(0.10)\end{array}$ & 4.48 & 1 & .04 & $\begin{array}{l}0.09 \\
(0.10)\end{array}$ & 1.10 & 1 & .29 \\
\hline \multicolumn{13}{|c|}{ Nestling sex was set as female $=0$ and male $=1$. } \\
\hline
\end{tabular}

\section{Discussion}

The current study found that egg survival increased as temporal distance between the day a focal egg was laid and the day of incubation onset within the clutch decreased. Prediction 1 stated that the egg viability until hatching increased with decreasing temporal distance and was constant after incubation onset, irrespective of temporal distance, therefore our results support Prediction 1 regarding the survival before incubation onset. On 
the other hand, egg viability until hatching decreased with increasing temporal distance after incubation onset, not supporting Prediction 1. Although we did not investigate parental behavior during food provisioning periods, there would be a trade-off regarding parental investment between parental incubation behavior for eggs and food provisioning for early-hatching siblings. The hatching failure of embryos laid after incubation onset might be caused by decreasing investment in incubation instead of increasing food provisioning for early-hatching siblings ("terminal egg neglect"; Evans and Lee 1991). Incubation onset before clutch completion caused hatching asynchrony and subsequently reduced survival of late-hatching nestlings until fledging in the analysis without the nestling sex as a predictor. This upheld Prediction 2, which stated that the survival of nestlings hatched from eggs laid before incubation onset until fledging would be constant but the survival of nestlings hatched from eggs laid after incubation onset until fledging would decrease with an increase of temporal distance. The analysis with the nestling sex did not detect a significant effect of hatching asynchrony on fledging success because the majority of unsexed nestlings, which died at early nestling stages, were likely to be low survival. Consequently, the survival of eggs from laying to fledging increased with decreasing temporal distance before incubation onset and decreased with increasing temporal distance after incubation onset, consolidating an assumption to test Prediction 3 which stated that egg size should increase over the laying sequence.

We found that egg volume increased over the laying sequence. This indicates that egg volume increased with increasing egg survival before incubation onset (positive correlation) and increased with decreasing egg and nestling survival after incubation onset (negative correlation). This pattern therefore represents a combination of proportionate investment before incubation onset and compensatory investment after incubation onset (Fig. 2c), indicating that female parents adopt different strategies in the laying period before and after incubation onset. It should be noted that the incubation onset in this study was detected by the touching, and as we mentioned above, although detecting the incubation onset by the touching led to a delay of one day in some cases compared with the temperature data logger (Appendix 1), the delay did not influence our conclusion qualitatively after implementing analyses that set the day of incubation onset ahead of one day.

It was suspected that parental egg volume compensation occurred after the hatching stage because nestlings demonstrated similar growth patterns irrespective of hatching asynchrony. Although this did not support Prediction 4 that late-hatching nestlings will grow faster than early-hatching nestlings, similar growth of latehatching nestlings to early-hatching nestlings might be a consequence of parental compensation. The influences of egg volume on nestling growth should be interpreted with caution as we did not investigate any other form of compensation such as elevation of testosterone level in eggs (Schwabl 1993) or preferential provisioning for late-hatching nestlings (Gottlander 1987). Collectively, our observational study offered the possibility that the strategy for maternal investment in eggs changes at the onset of incubation. Specifically, the parents perform "proportional investment" during the laying period before incubation onset and "compensatory investment" during the laying period after incubation onset in order to mitigate the disadvantages of delayed hatchling growth.

It remains unclear as to why wryneck parents in the study area performed "proportional investment" in eggs laid before incubation onset. Previous studies have proposed that extrinsic factors such as ambient temperature, microbial infection, and predation/nest site competition decrease the viability of eggs laid earlier in a clutch (Clark and Wilson 1981; Veiga 1992). When the ambient temperature exceeds the threshold temperature range 
$\left(24-26^{\circ} \mathrm{C}\right)$, embryos without parental incubation grow abnormally (Webb 1987; Veiga 1992). As our study area is situated in the temperate zone $\left(40^{\circ} 00^{\prime} \mathrm{N} ; 140^{\circ} 00^{\prime} \mathrm{E}\right)$, the average ambient temperature during our study did not surpass this threshold during the egg-laying period (Japan Meteorological Agency). However, as the maximum temperature occasionally surpassed the threshold, ambient temperature possibly decreased the survival of eggs laid before incubation onset. Microbial infection is also an extrinsic factor decreasing the viability of unincubated eggs (Cook et al. 2003; Ruiz-de-Castañeda et al. 2012). At our study site, the wrynecks were often found nesting in nest boxes after chestnut-cheeked starlings, Agropsar philippensis or Eurasian tree sparrows, Passer montanus, (Kato pers. obs.) had nested in the boxes. Reused nests may harbor pathogenic bacteria originating from food waste, feces, and the feather sheaths of earlier broods (Møller et al. 2015). Parental incubation may reduce microbial infection by keeping the eggs dry (D’Alba et al. 2010). Although eggs laid before incubation onset were at a relatively high risk of infection, we did not measure microbial proliferation in the nests. Predators and nest site competitors may have also lowered the survival rates of eggs laid before incubation onset (Clark and Wilson 1981). Although there were few predators for the nest box in our study area (Kato pers. obs.), the wrynecks were frequently evicted from their nest box by chestnut-cheeked starlings, Eurasian tree sparrows, and even conspecifics (Kato pers. obs.). Wrynecks might perform "proportional investment" in response to the pressure of nest site takeover before incubation onset. We observed that the eggs laid in certain clutches were substantially smaller than those in others (Appendix 4). The smaller eggs were often removed from the nest by nest-site competitors, predators, and/or parents before we could take measurements. Therefore, we could only measure smaller eggs in two clutches. Their volumes were $0.936 \mathrm{~cm}^{3}$ and $1.940 \mathrm{~cm}^{3}$ (mean of 201 eggs $=3.259 \mathrm{~cm}^{3}$ ). These eggs did not hatch and excluding these two from the dataset did not qualitatively alter the results. It is unclear whether the small eggs were the result of physiological constraints, maternal age, or a maternal minimal investment strategy for the eggs that were laid first.

The current study suggests that altricial wrynecks (Picidae) contend with asymmetry in egg and nestling survival between before- and after-incubation onset by allocating their egg volume investment according to the interrelated egg/nestling survival prospects and timing of incubation onset. In so doing, female parents adopt different parental investment strategies ("proportional investment" and "compensatory investment") before and after incubation onset. These behaviors might be adaptations to the physiological constraints wherein female birds cannot lay more than one egg per day. Although this study was observational, the findings did not contradict our hypothesis which were focused on the relationship between incubation onset and the egg/nestling survival. The findings of the present study indicate that maternal investment is, in fact, more flexible than previously believed. The experimental manipulation of exchanging eggs between nests or changing laying sequence would consolidate the hypothesis that we proposed and would provide new insight into the adaptive evolution of life history traits.

\section{Declarations}

\section{Acknowledgments}

We are grateful to Shigeo Ito, Yoko Ito, Sachiko Endo, Masayoshi Kamioki, Sayaka Hashima, Akira Tsutsumi, and the officers of Ogata village.

\section{Funding}


Not applicable

\section{Conflicts of interest}

Not applicable

\section{Ethics approval}

This study was approved by the Japanese Minister of Environment, Akita prefecture, Ogata village. All collected eggs and captured nestlings were handled and released immediately and safely after data collection.

\section{Consent to participate}

Not applicable

\section{Consent for publication}

All authors gave approval for publication.

\section{Availability of data and material (data transparency)}

We archived data files used in analyses in this study to Figshare:

https://doi.org/10.6084/m9.figshare.13889819

\section{Code availability (software application or custom code)}

Not applicable

\section{Authors' contributions}

TK designed the study, carried out the field work, conducted molecular experiments and statistical analyses, and drafted the manuscript; SM conceived the study and participated in discussion; RD participated in the field work; NK and KU participated in discussion.

\section{References}

1. Aldredge RA (2017) Incubation onset maintains survival of most embryos and growth and survival of latehatched young. Anim Behav 134:35-43

2. Arnold TW, Rohwer FC, Armstrong T (1987) Egg viability, nest predation, and the adaptive significance of clutch size in prairie ducks. Am Nat 130:643-653

3. Bebbington K, Kingma SA, Fairfield EA et al (2017) Consequences of sibling rivalry vary across life in a passerine bird. Behav Ecol 28:407-418

4. Burley N (1986) Sexual selection for aesthetic traits in species with biparental care. Am Nat 127:415-445

5. Carlisle TR (1985) Parental responce to brood size in a cichlid fish. Anim Behav 33:234-238

6. Clark AB, Wilson DS (1981) Avian breeding adaptations: hatching asynchrony, brood reduction, and nest failure. Q Rev Biol 56:253-277 
7. Clutton-Brock TH (1991) The evolution of parental care. Princeton University Press, Princeton

8. Coe BH, Beck ML, Chin SY et al (2015) Local variation in weather conditions influences incubation behavior and temperature in a passerine bird. J Avian Biol 46:385-394

9. Coleman RM, Gross MR, Sargent RC (1985) Parental investment decision rules: a test in bluegill sunfish. Behav Ecol Sociobiol 18:59-66

10. Cook MI, Beissinger SR, Toranzos GA et al (2003) Trans-shell infection by pathogenic micro-organisms reduces the shelf life of non-incubated bird's eggs: a constraint on the onset of incubation? Proc $R$ Soc $B$ Biol Sci 270:2233-2240

11. Cook MI, Beissinger SR, Toranzos GA, Arendt WJ (2005) Incubation reduces microbial growth on eggshells and the opportunity for trans-shell infection. Ecol Lett 8:532-537

12. D'Alba L, Oborn A, Shawkey MD (2010) Experimental evidence that keeping eggs dry is a mechanism for the antimicrobial effects of avian incubation. Naturwissenschaften 97:1089-1095

13. Djerdali S, Guerrero-Casado J, Tortosa FS (2016) Food from dumps increases the reproductive value of last laid eggs in the white stork Ciconia ciconia. Bird Study 63:107-114

14. Evans RM, Lee SC (1991) Terminal-egg neglect: brood reduction strategy or cost of asynchronous hatching. In: Int. Ornithol, Congr, pp 1734-1740

15. Gottlander K (1987) Parental feeding behaviour and sibling competition in the pied flycatcher Ficedula hypoleuca. Ornis Scand 18:269-276

16. Haig D (1990) Brood reduction and optimal parental investment when offspring differ in quality. Am Nat $136: 550-556$

17. Haight KL (2018) Increased investment in the defence of high-value offspring by a superorganism. Anim Behav 143:59-66

18. Hoyt DF (1979) Practical methods of estimating volume and fresh weight of bird eggs. Auk 96:73-77

19. Kahn NW, St. John J, Quinn TW (1998) Chromosome-specific intron size differences in the avian CHD gene provide an efficient method for sex identification in birds. Auk 115:1074-1078

20. Komdeur J, Daan S, Tinbergen J, Mateman C (1997) Extreme adaptive modification in sex ratio of the seychelles warbler's eggs. Nature 385:522-525

21. Lack D (1947) The significance of clutch-size. Ibis 89:302-352

22. Meathrel CE, Ryder JP (1987) Intraclutch variation in the size, mass and composition of ring-billed gull eggs. Condor 89:364-368

23. Møller AP, Soler JJ, Nielsen JT, Galván I (2015) Pathogenic bacteria and timing of laying. Ecol Evol 5:16761685

24. Oddie KR (2000) Size matters: competition between male and female great tit offspring. J Anim Ecol 69:903-912

25. Poole A (1982) Brood reduction in temperate and sub-tropical ospreys. Oecologia 53:111-119

26. R Core Team (2020) R: a language and environment for statistical computing. R foundation for statistical computing, Vienna, Austria. URL https://www.R-project.org/

27. Ricklefs RE (1967) A graphical method of fitting equations to growth curves. Ecology 48:978-983

28. Royle NJ, Smiseth PT, Kölliker M (2012) The evolution of parental care. Oxford University Press, Oxford 
29. Ruiz-de-castañeda AR, Vela Al, Lobato E, Briones V (2012) Early onset of incubation and eggshell bacterial loads in a temperate-zone cavity-nesting passerine. Condor 114:203-211

30. Sardell RJ, DuVal EH (2013) Differential allocation in a lekking bird: females lay larger eggs and are more likely to have male chicks when they mate with less related males. Proc R Soc B Biol Sci 281:10-16

31. Schielzeth H (2010) Simple means to improve the interpretability of regression coefficients. Methods Ecol Evol 1:103-113

32. Schwabl H (1993) Yolk is a source of maternal testosterone for developing birds. Proc Natl Acad Sci U S A 90:11446-11450

33. Slagsvold T (1982) Clutch size variation in passerine birds: the nest predation hypothesis. Oecologia 54:159-169

34. Slagsvold T, Lifjeld JT (1989) Hatching asynchrony in birds: the hypothesis of sexual conflict over parental investment. Am Nat 134:239-253

35. Slagsvold T, Sandvik J, Rofstad G et al (1984) On the adaptive value of intraclutch egg-size variation in birds. Auk 101:685-697

36. Stearns SC (1992) The evolution of life histories. Oxford University Press, Oxford

37. Stoleson SH, Beissinger SR (1995) Hatching asynchrony and the onset of incubation in birds, revisited. In: Power DM (ed) Current ornithology. Springer, Boston, pp 191-270

38. Styrsky JD, Eckerle KP, Thompson CF (1999) Fitness-related consequences of egg mass in nestling house wrens. Proc R Soc London Ser B Biol Sci 266:1253-1258

39. Svagelj WS, Lisnizer N, Borboroglu PG, Yorio P (2015) Variation in the size of eggs of kelp gulls (Larus dominicarius) at two colonies in Patagonia, Argentina. Waterbirds 38:92-98

40. Temme DH (1986) Seed size variability: a consequence of variable genetic quality among offspring? Evolution 40:414-417

41. Veiga JP (1992) Hatching asynchrony in the house sparrow: a test of the egg-viability hypothesis. Am Nat 139:669-675

42. Vinuela J (1997) Adaptation vs. constraint: intraclutch egg-mass variation in birds. J Anim Ecol 66:781

43. Wang JM, Beissinger SR (2009) Variation in the onset of incubation and its influence on avian hatching success and asynchrony. Anim Behav 78:601-613

44. Webb DR (1987) Thermal tolerance of avian embryos: a review. Condor 89:874-898

45. Westneat DF, Sherman PW (1993) Parentage and the evolution of parental behavior. Behav Ecol 4:66-77

46. Williams TD (1994) Intraspecific variation in egg size and egg composition in birds: effects on offspring fitness. Biol Rev 69:35-59

47. Wink M, Becker D, Tolkmitt D et al (2011) Mating system, paternity and sex allocation in Eurasian wrynecks (Jynx torquilla). J Ornithol 152:983-989

48. Winkler DW (1987) A general model for parental care. Am Nat 130:526-543

\section{Figures}



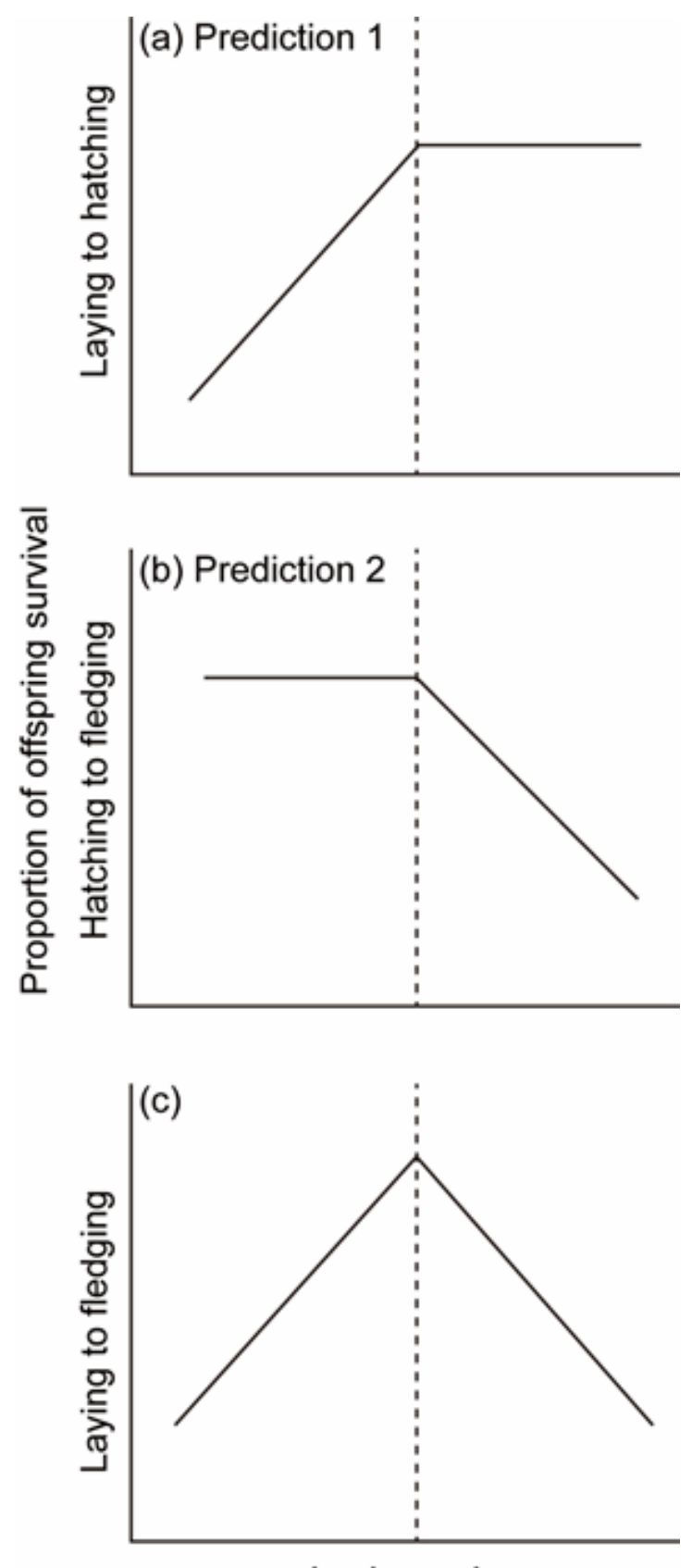

Laying order

\section{Figure 1}

Predictions for the relationships between the egg/nestling survival and laying order. The break line indicates the timing of incubation onset. (a) An increasing egg survival changes to a constant egg survival after incubation onset (Prediction 1). (b) A constant nestling survival changes to a decreasing nestling survival after incubation onset (Prediction 2). (c) Egg survival until fledging synthesizing (a) and (b). 
(a) Proportionate

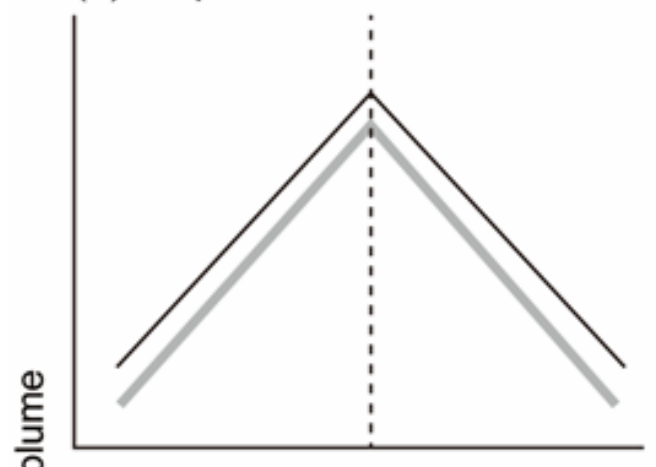

哥

\section{(c) Proportionate and Compensatory}

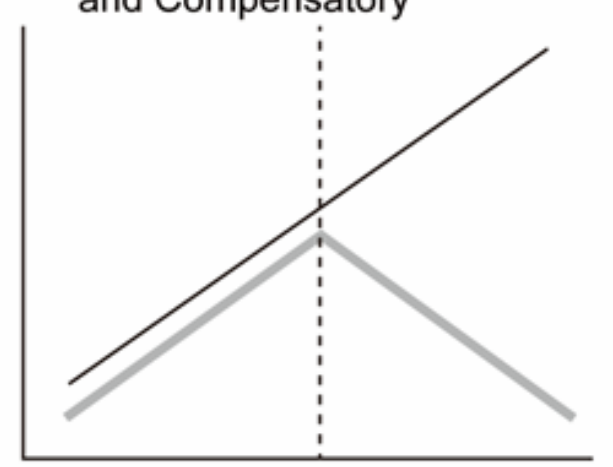

(b) Compensatory

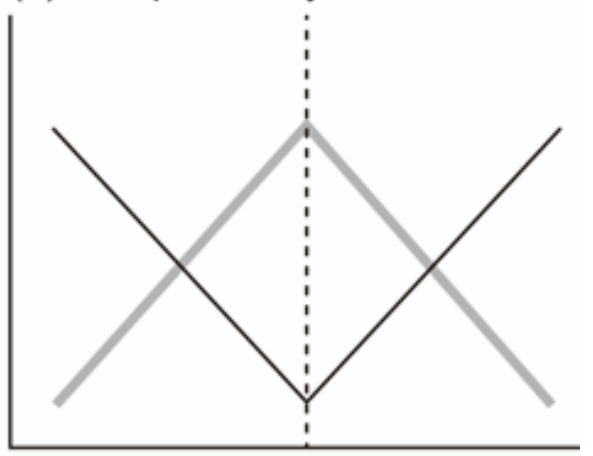

(d) Compensatory and Proportionate

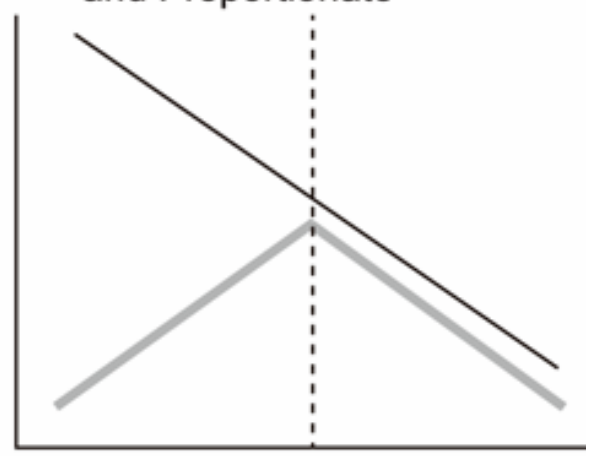

Laying order

\section{Figure 2}

Predicted egg volume from maternal proportionate and compensatory investment with respect to laying order and incubation onset. The solid black line and grey line indicate egg volume and egg survival until fledging (Fig. 1c), respectively. The break line indicates the timing of incubation onset. Predicted egg volume by (a) maternal proportionate investment and (b) compensatory investment. Predicted egg volume by maternal mixed strategies, (c) proportionate investment before compensatory investment, and (d) compensatory investment before proportionate investment, respectively.

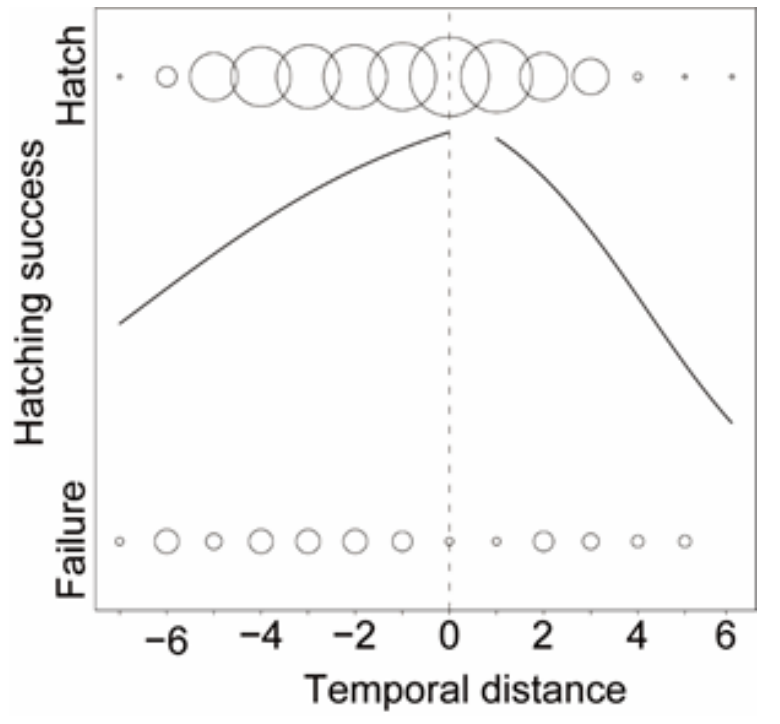

Figure 3 
Effect of incubation onset on egg hatching success. Broken lines: day of incubation onset. Circle size is proportional to sample size for samples 1-20.
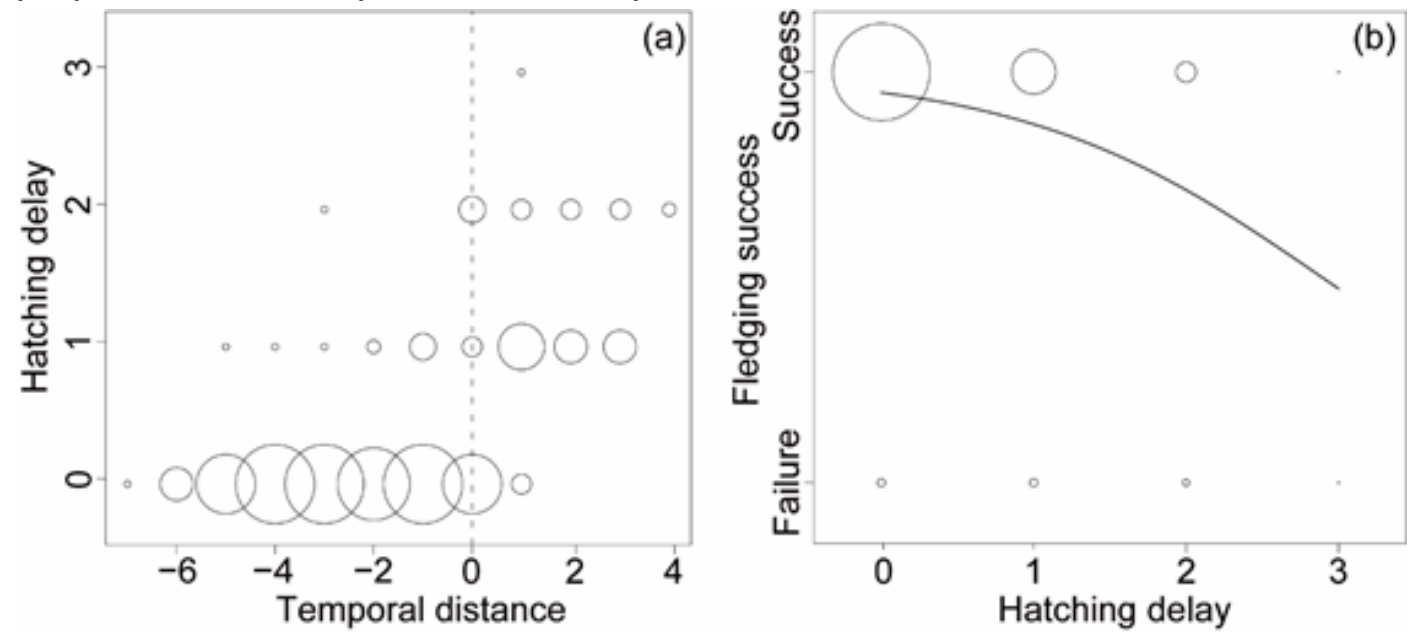

Figure 4

(a) Effect of incubation onset on hatching delay. (b) Effect of hatching delay on fledging success. Broken line: day of incubation onset. Circle size is proportional to sample size for samples 1-12 in (a) and samples 1-73 in (b).

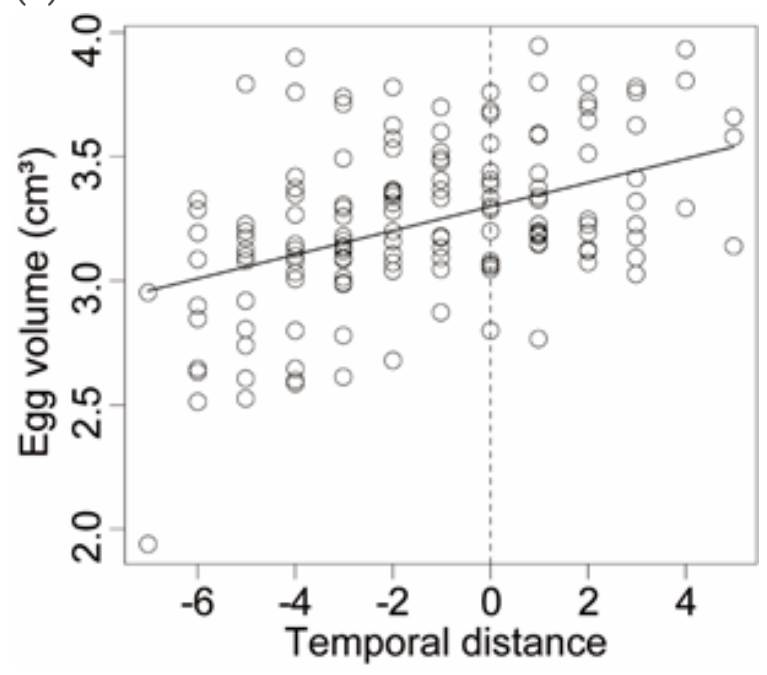

\section{Figure 5}

Effect of incubation onset on egg volume. Broken line: day of incubation onset. 